\title{
Caracterização do Geossítio Toca das Onças no município de Jacobina, Bahia, Brasil
}

\author{
Characterization of Geossite Onças's Cave in Jacobina, Bahia, Brazil
}

\author{
A. V. Araújo ${ }^{1,2}$; E. N. Eltink ${ }^{2,3}$; S. Magarão Jr. ${ }^{2,4}$; T. M. Espirito Santo ${ }^{2}$; E. \\ B. Oliveira2; E. M. Cajado ${ }^{2,5}$; H. G. Silva ${ }^{2}$ \\ ${ }^{1}$ Grupo IF de Estudos Espeleológicas (GRIFEE), Instituto Federal de Educação Ciência e Tecnologia do Sertão \\ Pernambucano, 56316-686, Petrolina - PE, Brasil \\ ${ }^{2}$ Sociedade Espeleologica Azimute, 44790-000, Campo Formoso - BA, Brasil \\ ${ }^{3}$ Colegiado de Ecologia, Universidade Federal do Vale do São Francisco-UNIVASF, 48970-000, Senhor do \\ Bonfim - BA, Brasil \\ ${ }^{4}$ Universidade Federal da Bahia-UFBa, Instituto de Geociências-IGeo, 40170-020, Salvador - BA, Brasil \\ ${ }^{5}$ Universidade do Estado da Bahia-UNEB, DCH, 41150-000, Jacobina - BA, Brasil
}

anddrevieira@gmail.com.br

(Recebido em 15 de setembro de 2018; aceito em 20 de novembro de 2018)

\begin{abstract}
A Toca das Onças tem se destacado na literatura científica por suas notáveis contribuições paleontológicas e arqueológicas, todavia poucas informações são conhecidas sobre o contexto socioeconômico e ambiental onde a mesma esta inserida. Diante disso, foram levantadas informações espeleológicas, culturais e turísticas, utilizando critérios de inventariação do patrimônio geológico, objetivando caracterizar a cavidade como geossítio a partir da quantificação e valoração dos elementos da geodiversidade. Os resultados da inventariação permitiu caracterizar o sítio como de alto valor científico e com baixo valor turístico, devido principalmente, à falta de infraestrutura e de acessibilidade. A partir destes resultados espera-se em trabalhos futuros a elaboração de propostas que estimulem o setor turístico no local e consequentemente programas com ações voltadas para a geoconservação do geossítio.
\end{abstract}

Palavras chaves: Inventariação, Toca das Onças, Geodiversidade.

The Onça's Cave has been highlighted in the scientific literature for its remarkable paleontological and archaeological contributions, however little information is known about the socioeconomic and environmental context where it is inserted. In the light of this, caving, cultural and tourist information were collected using criteria of inventorying of geological heritage, aiming at characterizing the cavity as geosite from the quantification and valuation of geodiversity elements. The results of the inventory allowed to characterize the site as having high scientific value and low tourism value, mainly due to the lack of infrastructure and accessibility. From these results it is expected in future Works, the elaboration of proposals that stimulate the tourist sector in this place and consequently programs with actions directed to geosite geoconservation.

Keywords: Inventory, Geodiversity, Onças's Cave.

\section{INTRODUÇÃO}

A Toca das Onças é um rico sitio paleontológico localizado no povoado de Caatinga do Moura, no município de Jacobina, na região norte da Bahia. Diversos espécimes que compõe a megafauna do pleistoceno foram coletados na Toca das Onças no final da década de 70. Dentre os fósseis coletados estão exemplares de Pampatherium paulacoitoi [1], Smilodon populator [2], e uma grande quantidade de restos fósseis de Eremotherium laurillardi com adultos, jovens e filhotes [3]. Além disso, restos de dois esqueletos humanos, também foram resgatados na mesma caverna com datação aproximada de 9 mil anos, portando traços 'africano-australomelanésios', 
demonstrando a relevância dessa caverna que contribui para o entendimento do processo de povoamento do continente Americano [4, 5].

Apesar de expressiva importância paleontológica e arqueológica, esse sítio carece de informações elementares que possam dar subsídios a sua contribuição no trinômio geodiversidade, geoturismo e geoconservação. Em uma concepção ampla o termo geodiversidade pode ser definido como a variedade de ambientes e processos geológicos relacionados a seu povo e cultura [6]. Entende-se que as relações entre os elementos da geodiversidade com as sociedades e culturas locais influenciam e interferem diretamente no potencial e na qualidade dos produtos turísticos [7]. Nesse contexto, este trabalho tem como objetivo fazer um levantamento das principais informações geoespeleológicas, histórico-culturais e turísticas, para a elaboração de um inventario da Toca das Onças, buscando elementos que permitam sua possível inclusão como sítio de relevante geodiversidade. Trabalhos de caracterização e inventariação consistem no primeiro passo de qualquer iniciativa de geoconservação ao atrelar um maior conhecimento do meio natural e é a partir do conhecimento e da valorização do patrimônio natural que os usuários e as populações residentes poderão e deverão usá-lo de forma correta e sustentável [8].

\section{MATERIAL E MÉTODOS}

Para inventariação e caracterização do geossítio foi utilizada a metodologia de inventário de detalhe [9]. Consistem em observações detalhadas, com o objetivo de levantar informações específicas sobre o sítio, com o intuito de elaborar ferramentas e estratégias de manejo. As informações levantadas são resumidas no quadro a seguir.

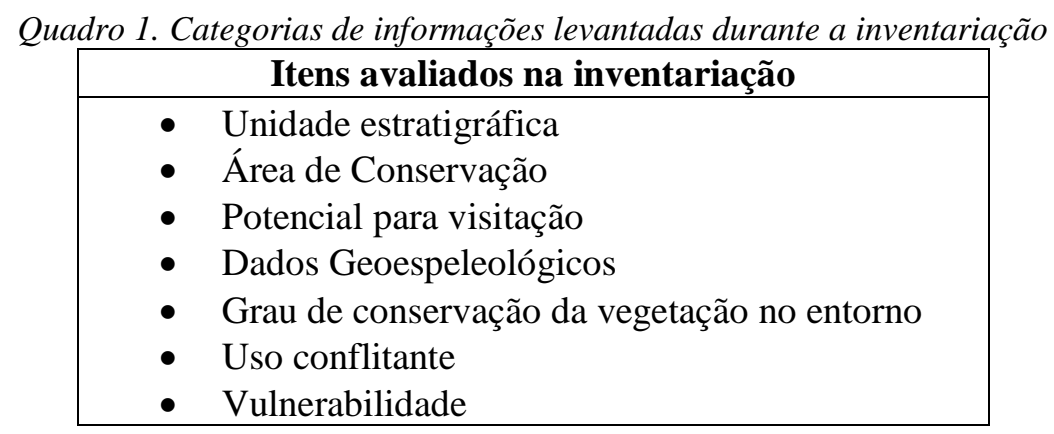

Realizou-se etapa de campo com a prospecção da área e topografia em detalhe da caverna e, posteriormente, elaboração de mapas digitais e levantamento de informações socioeconômicas através da literatura e de observações in loco sobre habitações, saneamento e atividades ligadas à economia local. Os dados foram inseridos no aplicativo GEOSSIT - CPRM do serviço Geológico do Brasil. [10]

\section{RESULTADOS E DISCUSSÃO}

\subsection{GEOESPELEOLOGIA}

O sítio Toca das Onças (WGS84-UTM $300604 \mathrm{~m} \mathrm{E;} 8791416 \mathrm{~m} \mathrm{~N}$ ) é formado por duas cavidades naturais não conectadas que estão situadas no povoado de Caatinga do Moura, à margem esquerda do rio Caatinga do Moura, um afluente do rio Salitre. A caverna está inserida no contexto geológico das coberturas Neoproterozóicas que englobam as rochas carbonáticas da Formação Salitre, pertencente ao grupo Una (Figuras 1 e 2).

Os dados espeleométricos obtidos através da topografia revelam que a caverna possui uma única entrada vertical com um desnível de $4,5 \mathrm{~m}$ situada no interior de uma dolina de colapso. A área total da entrada é de aproximadamente $16 \mathrm{~m}^{2}$. As características da abertura da caverna permitiram o acesso ou queda de animais de vários portes incluindo megamamíferos. Como pode ser observado na planta baixa do mapa topográfico (Figura 3) a caverna possui um único salão com desenvolvimento linear de $23 \mathrm{~m}$ e volume aproximado de $60 \mathrm{~m}^{3}$. O salão é parcialmente iluminado devido às dimensões da abertura de entrada e à presença de uma claraboia de pequena 
dimensão adjacente a abertura da entrada. Cartelle \& Bohorquez (1982) [11] sugerem que a caverna possuía um pequeno curso de água já desaparecido. Através da topografia realizada não foi possível identificar evidências de tal curso de água pretérito, no entanto, notou-se que a caverna foi bastante alterada, na sua camada sedimentar, devido a seguidas escavações em busca de fósseis. Observaram-se acúmulos de sedimento residual proveniente de escavações por todo o perímetro do salão.

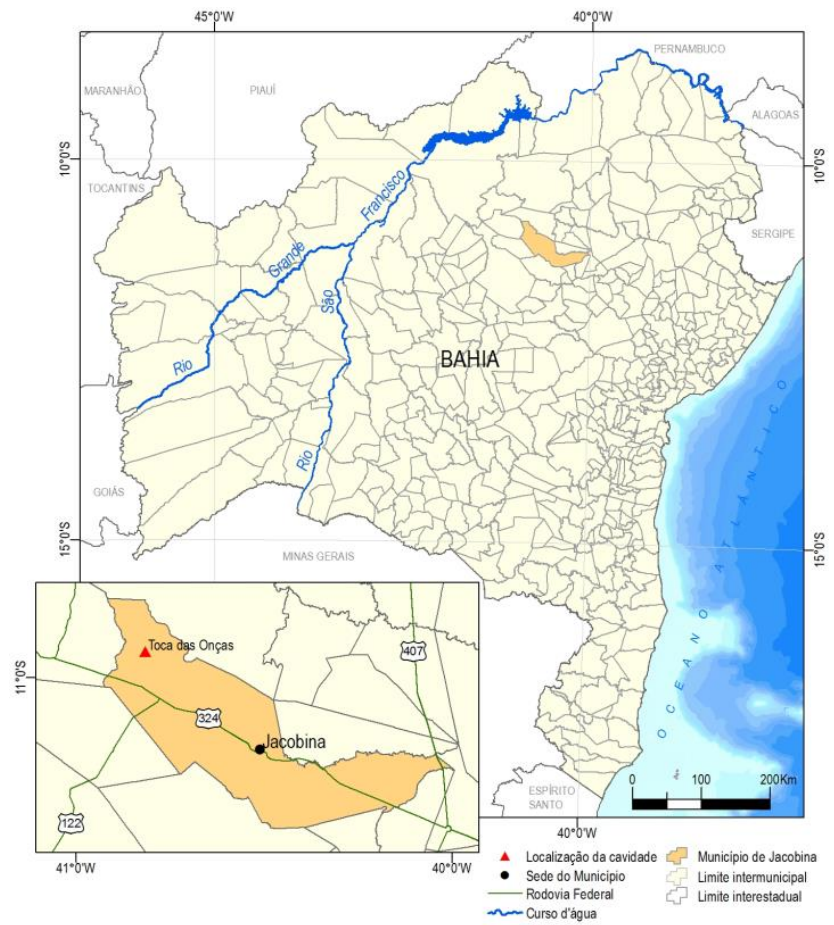

Figura 1: Localização do município de Jacobina na Bahia e do sítio Toca das Onças. Fonte da Base: SEI, 2013; IBGE, 2012; DNIT, 2016. Elaboração: Sociedade Espeleológica Azimute-SEA.

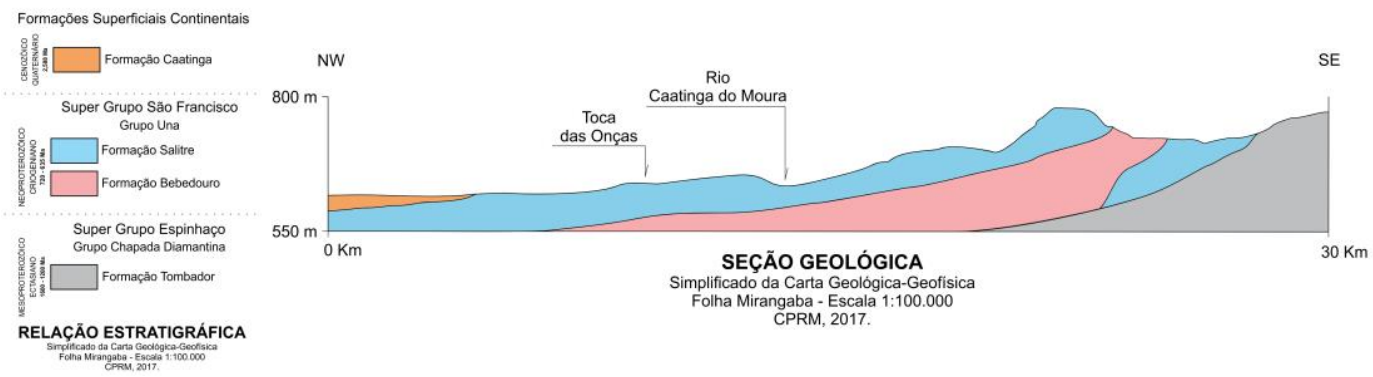

Figura 2: Contexto geológico da Toca das Onças, Jacobina-BA. Fonte: Sociedade Espeleológica Azimute-SEA.

De acordo com Auler et al. (2006) [12], os fósseis podem ser introduzidos nas cavernas brasileiras de cinco diferentes formas: i) Por predadores que usam a caverna como covil; ii) pela morte de animais que entraram na caverna em busca de água ou abrigo temporário e não conseguiram sair; iii) pela morte de animais que vivem na caverna; iv) transportados por águas através de enxurradas que entram na caverna; v) pela queda de animais em abismos verticais. Dadas às características da entrada da Toca das Onças e do porte dos fósseis que foram coletados em seu interior é provável que a caverna tenha funcionando como uma armadilha natural, provocando a queda de alguns desses animais, embora não seja possível descartar as hipóteses de transporte pela água e até mesmo a possibilidade de carnívoros capazes de escalar o pequeno desnível e ter utilizado a caverna como abrigo. 


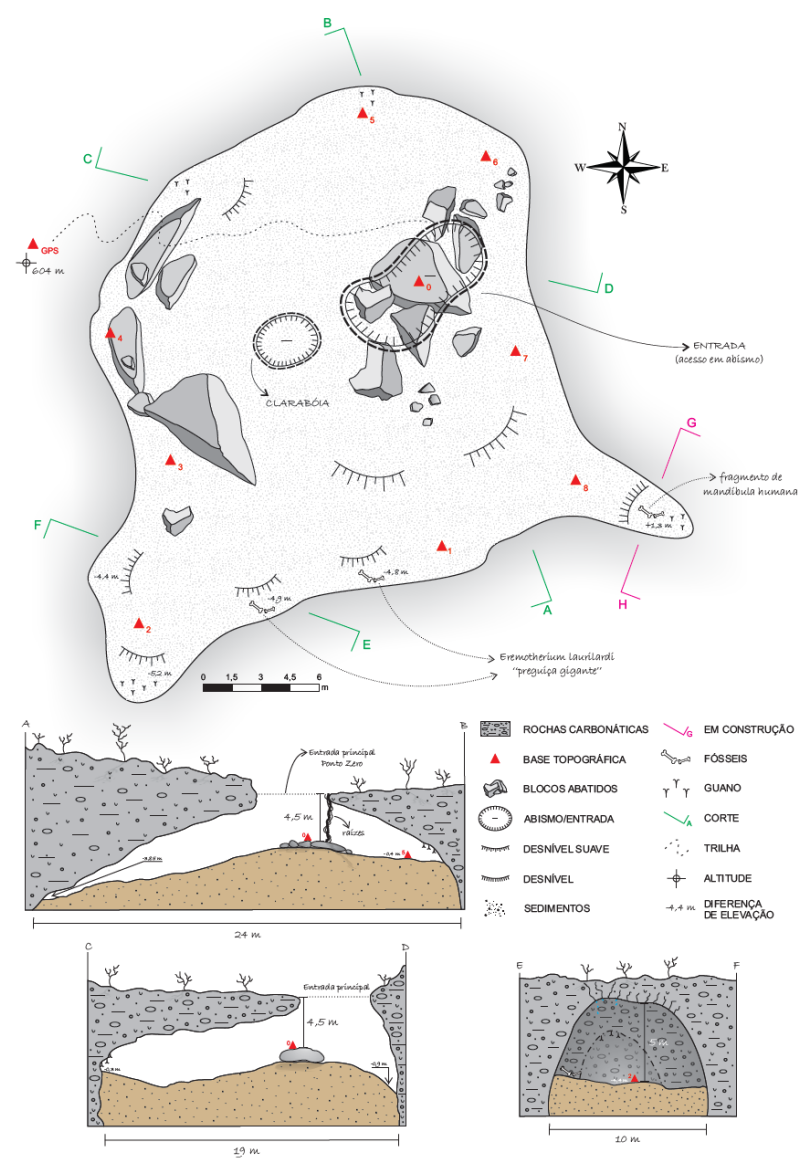

Figura 3: Planta baixa e cortes da Toca das Onças. Fonte: Sociedade Espeleológica Azimute-SEA.

No trabalho de campo, realizado em janeiro de 2018, identificou-se em superfície dezenas de fragmentos ósseos remanescente das coletas paleontológicas realizadas desde o final da década de 70. A maior parte constituía-se de fragmentos de costelas, dentes, e pedaços de ossos longos de animais da megafauna. Surpreendentemente, em um pequeno recuo na parte sudeste do salão, encontrou-se fragmentos de ossos pós cranianos, aparentemente humanos, associados a parte do corpo da mandíbula esquerda, com dentes incisivos, caninos, pré-molares e molares implantados nos alvéolos (Figura 4). 


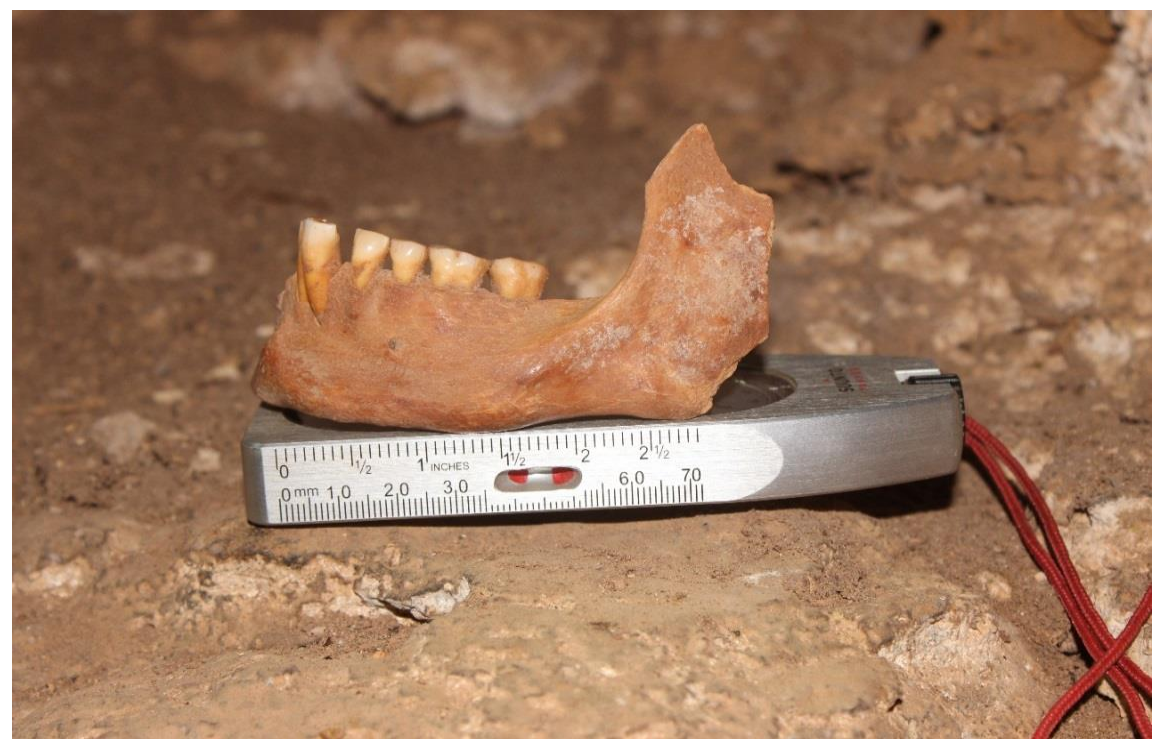

Figura 4: Fragmento de mandíbula humana encontrado durante a topografia da Toca das Onças em janeiro de 2018. Fonte: Sociedade Espeleológica Azimute-SEA.

Devido ao potencial científico desse achado e diante do risco eminente da retirada desse material por caçadores de fósseis amadores e curiosos que acompanhavam os trabalhos topográficos na Toca das Onças, o material foi encaminhado para Universidade Federal do Vale do São Francisco (UNIVASF), no município de Senhor do Bonfim, BA, a fim de assegurar sua salvaguarda, após o tombamento em coleção científica, servindo de base para futuros estudos. Destaca-se a importância desse achado quando da topografia da caverna por permitir, novas, informações sobre o processo de deposição dos espécimes fósseis no interior da cavidade.

\subsection{GEOTURISMO}

O geoturismo e o espeleoturismo são uma ótima ferramenta para divulgação, conservação e valorização da geodiversidade. E precisa ser trabalhado em conjunto com toda a sociedade, para que todos tenham noção da importância da conservação e proteção dos elementos da geodiversidade. Nesse sentindo, é preciso entender um pouco do conceito de geoturismo. E segundo Hose (1995), o geoturismo é definido como a "provisão de serviços e facilidades interpretativas no sentindo de possibilitar aos turistas a compreensão e aquisição de conhecimentos de um sítio geológico e geomorfológico ao invés de simplesmente apreciação estética." (apud Freitas, 2015, p. 20) [13].

Devido ao seu valor científico, a Toca das Onças tem importância no contexto do geoturismo, que de acordo com Mochiutti et al. (2012) [14], está muito ligado a avaliações qualitativas, seja pelo seu valor científico, ou pelos elementos inventariados da geodiversidade de valor turístico, didático e/ou cultural.

Por ter sua acessibilidade e infraestrutura precária, atualmente é inviável a execução de um turismo sustentável na Toca das Onças. Para que o geoturismo seja trabalhado a curto e médio prazo, faz-se necessário melhorar o acesso ao local do geossítio, já que grande parte do trajeto é em estrada de chão em péssimo estado. E para despertar o interesse do turista e fazer com que ele visite o local, é preciso tornar o atrativo visível, acessível e passível de interesse e entendimento com pontos de apoio e divulgação do local. Outro ponto que dificulta o geoturismo na Toca das Onças é o acesso ao interior da caverna, já que o acesso é vertical com um desnível de 4,5 m, e hoje é feito por uma raiz de uma árvore que cresceu junto à parede da dolina.

Mesmo com toda a dificuldade para desenvolver o turismo na região, algo já está sendo feito. Ao longo da estrada não pavimentada é possível encontrar placas de sinalização indicando o caminho, que vão até alguns metros da entrada da Toca das Onças. 


\subsection{ASPECTOS SOCIOECONÔMICOS}

O povoado de Caatinga do Moura onde está situada o sítio da Tocas das Onças apresenta, segundo o IBGE, 2011 [15] uma população de 8.135 habitantes. Poucas são as ruas com calçamento e esgotamento sanitário. O setor de serviços atende uma demanda básica com estabelecimentos de matérias de construção, farmácias e mercadinhos ao se distanciar da sede do povoado percebe-se uma predominância de atividades ligadas à agricultura familiar como culturas de sisal, banana e de mandioca. Destaca-se também a fabricação e comercialização do doce de banana, marmelo e manga.

A principal atividade cultural é a Festa do Bom Jesus da Glória, realizada anualmente no dia 06 de agosto, a qual envolve uma programação religiosa caracterizada pela lavagem das escadarias da igreja e uma programação com a fanfarra dos colégios da localidade onde estudam 554 alunos da educação infantil ao médio [16].

\section{CONCLUSÃO}

A Toca das Onças é caracterizada como geossítio em consequência do seu alto valor científico, sobretudo devido às informações paleontológicas e arqueológicas de materiais coletados em seu interior. Os dados geoespeleológicos, culminando com a produção de um mapa digital da Toca das Onças, os levantamentos de informações sobre a viabilidade turística e os dados socioeconômicos levantados no presente trabalho foram utilizados na inventariação do sítio através do aplicativo GEOSSIT-CPRM do Serviço Geológico do Brasil. Apesar de preliminares esses dados aqui levantados podem ser utilizados em trabalhos futuros para a quantificação e valoração e a partir disso delinear projetos que visem a geoconservação do geossítio.

\section{AGRADECIMENTOS}

Agradecemos a todos os participantes da Expedição SEA 01/2018 (Leonardo Bamberg, Danilo Araújo, Edna Rocha, Thais Cursino, Rafaela Bonfim, Jessica Carolyne, Mateus Martins) e um agradecimento especial à Claudiney Dias, pelas dicas com a localização da fazenda onde está a Toca das Onças, ao Victor Valverde e ao Gilson Araújo, pelo auxilio com as técnicas verticais.

\section{REFERÊNCIAS BIBLIOGRÁFICAS}

1. Cartelle C. Pampatherium paulacoutoi, uma nova espécie de tatu gigante da Bahia, Brasil (Edentata, Dasypodidae). Rev Bras Zool. 1985;2(4):229-254.

2. Cartelle C, Abhuid VS. Novos espécimes brasileiros de Smilodon populator (Lund, 1842), Carnivora, Machrairodontinae: morfologia e conclusões taxonômicas. In: Congresso Brasileiro de Paleontologia, 11, 1989, Curitiba, PR. 1989. p. 607-620.

3. Lessa G, Cartelle C, Faria H. Gonçalves P. Novos achados de mamíferos carnívoros do pleistoceno final-Holoceno em grutas calcárias da Bahia. Acta Geol Leopoldensia. 1998;21(46/47):157-169.

4. Neves WA, Meyer D, Pucciarelli HM. The Contribution of the Morphology of Early South and North American Skeletal Remains to the Understanding of the Peopling of the Americas. Amer J Physical Anthrop. 1993;16(Suppl):150-51.

5. Hubbe M, Neves WAD, Atupi, JPV, Cartelle C, Mya APS. A New Early Human Skeleton from Brazil: Support for the "Two Main Biological Components Model" for the Settlement of the Americas. Current Res Pleistocene. 2004;21:77.

6. Stanley M. Welcome to the 21st century. Geodiversity. Update, 1, p. 1-8; 2001.

7. Nascimento HHO, Silva JRM, Moreira AS. Geodiversidade em áreas protegidas: um levantamento do potencial geoturístico do Parque Estadual das Carnaúbas/CE. In: Rasteiro MA, Teixeira-Silva CM, Lacerda SG, organizadores. $34^{\circ}$ Congresso Brasileiro de Espeleologia; 2017. Ouro Preto, Campinas: SBE; 2017. p. 619-627.

8. Piekarz GF. Geoturismo no Karst. Curitiba: MINEROPAR - Minerais do Paraná; 2011. 121 p.

9. Pereira RGF. A Geoconservação e desenvolvimento sustentável na Chapada Diamantina (Bahia Brasil) [Tese] Braga: Universidade do Minho, Escola de Ciências; 2010. 317p.

10. GEOSIT - Cadastro de sítios geológicos. Disponível em http://www.cprm.gov.br/geossit/geossitios. Acesso em 10 jul.2018. 
11. Cartelle C, Borhórquez GA. Eremotherium laurillardi Lund, 1842. Parte I - Determinação específica e dimorfísmo sexual. Iheringia. 1982;7:45-63.

12. Auler AS, Piló LB, Smart PL, Wang X, Hoffmann D, Richards DA, Edwards RL, Neves WA, Cheng H. U-series dating and taphonomy of Quaternary vertebrates from Brazilian caves. Palaeogeogr Palaeoclimatol Palaeoecol. 2006;240:508-522.

13. Moura-Fé MM. Geoturismo: Uma proposta de turismo sustentável e conservacionista para a Região Nordeste do Brasil. Soc. \& Nat. 2015 jan/abr;27(1):53-66, doi:10.1590/1982-451320150104.

14. Mochiutti NF, Gilson BG, Moreira JC, Lima, FF, Freitas FI. Os Valores da Geodiversidade: Geossítios do Geopark Araripe/CE. Anuário do Instituto de Geociências (UFRJ). 2012;35(1):173-189, doi:10.11137/2012_1_173_189.

15. IBGE. Sinopse preliminar do censo demográfico: Brasil. Rio de Janeiro, RJ; 2011.

16. Silva PV. Ser leitor na roça: histórias de leituras na Caatinga do Moura. [Dissertação] Salvador: Universidade do Estado da Bahia, UNEB; 2009. 